\title{
Potential of moderately compressed wood as an elastic component of wooden composites
}

Aoi HIRANO ${ }^{1}$, Eiichi OBATAYA ${ }^{1}$, and Koji ADACHI ${ }^{2}$

${ }^{1}$ Graduate School of Life and Environmental Sciences, Tsukuba University, Tsukuba 305-8572, Japan

Corresponding author: Eiichi OBATAYA

Email: obataya.eiichi.fu@u.tsukuba.ac.jp

${ }^{2}$ Institute of Wood Technology, Akita Prefectural University, Noshiro 016-0876, Japan

\begin{abstract}
Japanese cedar wood was moderately compressed by $50 \%$ in the radial (R) direction. The compressed wooden blocks were glued into the form of a beam with $\mathrm{R}$ directions aligned in the longitudinal direction of the beam. The compressed wooden beam (CR) showed excellent ductility and elasticity comparable to synthetic rubbers. The elastic deflection of the CR was further increased when the tensile side was reinforced by a thin compressed wooden plate (CL), because this ensured that the CR was always in a compressed state while tensile stress was supported by the CL. The $\mathrm{CR}+\mathrm{CL}$ composite exhibited large deflections 10 times greater than that of the original cedar lumber, a Charpy value corresponding to the high amount of energy absorbed in impact bending comparable to that of densified wood, and a large critical bending work exceeding that of uncompressed wood in the direction of the fiber. The soft and durable nature of the composite beam was attributed to the softness and elasticity of the moderately compressed wood, in which the folded cell walls behaved as flat springs.
\end{abstract}




\section{Introduction}

Wood is a typical honeycomb material that can be densified by compression in the radial $(\mathrm{R})$ or tangential (T) directions. By this densification, the rigidity and strength of wood in the longitudinal (L) direction are enhanced with increased density. In addition, the densified surface exhibits excellent hardness and abrasion resistance. While the shape recovery of compressed wood was problematic, various methods of shape fixation, such as resin impregnation and hydrothermal treatments, have been established (Stamm et al. 1941, Stamm et al. 1946, Inoue et al. 1993, Ito et al. 1998). Therefore, densification is a promising method for the utilization of wood: the conversion of abundant low-density softwood into heavy, hard, and strong lumber. The advantageous features of compressed wood and methods of shape fixation were reviewed by Sandberg et al. (2012).

Another important feature of densified wood is ductility against tensile loading in the direction of compression. In general, wood is fragile when loaded in tension in the transverse direction. However, when a wood is compressed prior to use, it can bear large tensile stains because the folded cell walls can be expanded. The ductility of densified wood eases the molding of wood (Nakamura et al. 2009, Kutner et al. 2015) and the fabrication of cylindrical wooden columns (Haller et al. 2013, Wehsener et al. 2014).

Little attention has been paid to the elasticity of moderately densified wood. When a wood is completely densified, it cannot undergo large compressive deformations because the porous cellular structure disappears, permitting little change in the shape of the cells. In contrast, when a wood is moderately densified, the porous structure remains and the folded cell walls can act as flat springs. Therefore, the moderately densified wood should deform elastically under compression. If so, the densified wood could be used as a soft and elastic component in wooden furniture and constructions. In this study, we analyze the compressive elasticity of compressed wood and the application thereof in flexible wooden beams.

\section{Materials and methods}

\section{Compression test}

Japanese cedar wood (Cryptomeria japonica) was cut into cubes with dimensions of $10 \mathrm{~mm}(\mathrm{~L}) \times 10$ $\mathrm{mm}(\mathrm{T}) \times 10 \mathrm{~mm}(\mathrm{R})$. The air-dry densities of the cubes were $353-397 \mathrm{~kg} / \mathrm{m}^{3}$. The specimens were conditioned at $25^{\circ} \mathrm{C}$ and $60 \%$ relative humidity (RH) for more than 1 week and then compressed in the $\mathrm{R}$ direction by a universal testing machine at a crosshead speed of $2 \mathrm{~mm} / \mathrm{min}$. After removing the 
load, the specimens were compressed again to determine the remaining plastic strain. The compression rate was defined as the percentage of compressive strain experienced after the removal of the load.

\section{Fabrication of composite beams}

Figure 1 illustrates the structure of the composite beams tested in this study. A Japanese cedar lumber was cut into cubes measuring $30 \mathrm{~mm}$ on a side. The air-dry density of the lumber was 312 $424 \mathrm{~kg} / \mathrm{m}^{3}$. The cubes were conditioned under humidity until the moisture content reached or exceeded $15 \%$; they were then compressed in the R direction using a press machine at $100^{\circ} \mathrm{C}$. The compression rate varied from 23 to $65 \%$, and some compressed wooden blocks were subjected to compression test described later. The uncompressed and compressed wooden blocks were glued into a beam with $\mathrm{R}$ directions aligned with the longitudinal direction of the beam. Polyvinyl acetate (PVAc) emulsion glue was used, and the glued blocks were pressed at $0.5 \mathrm{MPa}$ until the glue solidified. Hereafter, the uncompressed and compressed glued beams are referred to as UR and CR, respectively.

Another cedar lumber $\left(330-377 \mathrm{~kg} / \mathrm{m}^{3}\right)$ was used to fabricate reinforcement plates (CL) in which the fiber direction is aligned in the longitudinal direction. The lumber was cut into plates measuring 3-9 $\mathrm{mm}(\mathrm{R}) \times 30 \mathrm{~mm}(\mathrm{~T}) \times 200 \mathrm{~mm}(\mathrm{~L})$. These plates were compressed in the R direction by $70 \%$ in the manner described above.

Finally, the UR and CR were combined with the CL using PVAc glue, and cut into rods. In this article, the composite beams are referred to as UR+CLx and CR+CLx, where $\mathrm{x}$ indicates the relative thickness of the CL, varying from 0.1 to 0.3 . The dimensions of tested beams are listed in Table 1 .

\section{Three-point bending test}

A three-point bending test was conducted at $25^{\circ} \mathrm{C}$ and $60 \% \mathrm{RH}$ to determine the bending Young's modulus $(E)$ and elastic deflection of the beams. The effective span was $140 \mathrm{~mm}$ and the crosshead speed was $2 \mathrm{~mm} / \mathrm{min}$. For the composite beams, the bending load was applied as the CL supported the tensile stress while the UR and CR were compressed. The elastic deflection was determined by repeating the bending test. The beams were loaded and offloaded with stepwise increases in the deflection, and the remaining deflection was recorded after each loading process. With considering the straightness and dimensions of the fabricated beams, six samples each were selected for testing 
$\mathrm{UL}$ and $\mathrm{CR}$, five for $\mathrm{CR}+\mathrm{CL}_{0.1}$, four each for $\mathrm{UR}+\mathrm{CL}_{0.1}$ and $\mathrm{CR}+\mathrm{CL}_{0.3}$, and at least two each for the other beams. Some composite beams were bent at different loading levels, with deflections intermittently recorded for $48 \mathrm{~h}$ after the removal of load.

\section{Four-point bending test}

The composite beams $(\mathrm{CR}+\mathrm{CL})$ were subjected to a four-point bending test, with maximum surface strains measured to determine the position of a neutral plane under pure bending. The total span was $150 \mathrm{~mm}$ and the crosshead speed was $5 \mathrm{~mm} / \mathrm{min}$. Since the compressive strain of CR exceeded $10 \%$, a conventional strain gage could not be used. Therefore, the changes in beam shape were intermittently photographed by a digital camera (SONY, NEX 5N), and the surface strain was determined from the photographs $(4912$ pixel $\times 3264$ pixel) by using image analysis software (Image-J). For image clarity, two black pencil leads $(0.2 \mathrm{~mm}$ thick) were vertically attached to the side surface of the beam, and the slight distortion aberration (1.85\%) was corrected using editing software (Adobe Photoshop) prior to the image analysis.

\section{Impact bending test}

In the manner described above, thicker beams $(30 \mathrm{~mm} \times 30 \mathrm{~mm} \times 300 \mathrm{~mm})$ were fabricated and subjected to impact bending tests using a conventional Charpy tester (Toyo Seiki Co.). A hammer of given weight was dropped upon the beam and the loss of its potential energy was calculated by comparing its height before and after the impact. The lost energy of the hammer i.e. the energy absorbed by the bending event $(\Delta E)$ was then divided by the area of cross section of the beam $(A)$ to give Charpy value $(\triangle E / A)$. The effective span was $240 \mathrm{~mm}$, and the angle, mass, and rotation radius of the impact hammer were $138.5^{\circ}, 11.135 \mathrm{~kg}$ and $0.6 \mathrm{~m}$, respectively. Three samples were used for testing the CR and two each for the other beams.

\section{Results and discussion}

\section{Softness and compressive elasticity of compressed wood}

Compressed wood is generally regarded as rigid and hard, because densified wood shows enhanced rigidity in the $\mathrm{L}$ and $\mathrm{T}$ directions as well as a hardened surface. However, when a wood is only moderately compressed in the $\mathrm{R}$ direction, it becomes soft and elastic under compression in the $\mathrm{R}$ direction. Figure 2 shows the compressive stress-strain diagram for uncompressed and compressed 
cedar woods. The clear yielding point in the stress-strain curve of the uncompressed wood indicates the buckling of wood cell walls at small (1-2\%) strains, and above $2 \%$, most of strain remains plastically because the buckled shape of the cell walls are not elastically recovered. Therefore, after the first compression up to $6 \%$, it starts to be compressed at $4 \%$ strain in the second compression. In this case, $4 \%$ strain remains unrecovered while $2 \%$ is elastically recovered after the first compression.

In contrast, when a wood is previously compressed by $50 \%$, it shows an extremely low compressive Young's modulus, and imposed compressive deformation is elastically recovered after the removal of load. The density of the cedar wood tested was $353-397 \mathrm{~kg} / \mathrm{m}^{3}$; the compressive strain required for complete densification is at least $73 \%$. Therefore, when the wood is moderately compressed by $50 \%$, most of the wood cells are buckled and folded, but not completely densified. As these incompletely densified cells act as flat springs, the moderately compressed wood shows a low Young's modulus and large elastic recovery.

As exhibited in Figure 2, compressive elasticity can be evaluated by repeated compression test. Here the maximum strain in the first compression is defined as "initial strain", whereas the starting point in the second compression is defined as "remaining strain". In Figure 3, the remaining strains of the uncompressed and compressed wood samples are plotted against the initial strains. When a material is perfectly elastic, the remaining strain should be zero. The elastic deformation of the uncompressed wood was limited to $2 \%$, above which most strain remains plastically. On the other hand, the compressed wood shows a wider elastic range. When a wood is previously compressed by $49-65 \%$, it shows a maximum elastic (or recoverable) strain of $15 \%$ or greater. Regarding the compressive Young's modulus and elastic range, the moderately compressed wood behaves as a rubber-like material.

\section{Bending performance of composite beam}

Figure 4 exhibits the ductile nature of the composite beam tested $\left(C R+\mathrm{CL}_{0.1}\right)$. Although the uncompressed beam breaks at a small deflection, the $\mathrm{CR}+\mathrm{CL}_{0.1}$ experiences extremely large bending without visible failure. Figure 5 shows the load-deflection curves of the different materials tested. The UL and CL are rigid and strong, but the maximum deflections are 4-6 $\mathrm{mm}$. On the other hand, CR is extraordinarily soft and ductile. It shows a very low average Young's modulus of $24 \mathrm{MPa}$, comparable to that of hard rubbers, and does not break until the crosshead reaches the lower dead 
point. When the tensile side of $C R$ is reinforced with $C L(C R+C L)$, the flexural rigidity of the beam is effectively enhanced while the maximum deflection decreases with the increased relative thickness of the CL. However, the $\mathrm{CR}+\mathrm{CL}_{0.3}$ sample remains softer and more ductile than UL. In addition, the critical bending work, i.e., the lower area of the load-deflection curve, is at least three times greater than that of UL.

In Figure 6, the flexural rigidities $(E I)$ of the materials tested are plotted against elastic deflection. The elastic deflection indicates the maximum deflection that can be elastically recovered after the removal of load. The UL and CL are rigid, but experience elastic deflections of $3 \mathrm{~mm}$ at most. By combining UR and CL, the elastic deflection is improved, but still limited at $6 \mathrm{~mm}$. By contrast, the CR allows large elastic deflection of $12 \mathrm{~mm}$ with a flexural rigidity of $1 \%$ or less than that of UL and CL. By combining $\mathrm{CR}$ and $\mathrm{CL}\left(\mathrm{CR}+\mathrm{CL}_{0.1}\right)$, both the flexural rigidity and elastic deflection are enhanced, and thicker $\mathrm{CL}\left(\mathrm{CR}+\mathrm{CL}_{0.2}, \mathrm{CR}+\mathrm{CL}_{0.3}\right)$ allows further increase in the rigidity whereas the elastic deflection decreases with increasing the thickness of CL.

Figure 7 shows the Charpy value, an indicator of impact strength, of the materials tested. Since the flexural rigidity of wood is enhanced by densification, the CL shows a larger Charpy value than UL does. The Charpy value of UR+CL exceeds that of UL because much energy is absorbed by the compressive deformation of UR. However, the UR+CL beams were completely fractured and its folded shape remained unrecovered after the impact, because the UR deforms plastically under compression. On the other hand, the $\mathrm{CR}+\mathrm{CL}_{0.1}$ and $\mathrm{CR}+\mathrm{CL}_{0.2}$ show large Charpy values, several times greater than that of UL. It should be emphasized that the excellent impact strength of CR+CL does not result from plastic deformation, but from the improved ductility and elasticity of CR, as exhibited in Fig. 6. In fact, a composite beam $\left(\mathrm{CR}+\mathrm{CL}_{0.1}\right)$ showed no visible failure and its shape was recovered almost completely after the impact test. Strictly speaking, the number of tested specimens was not enough to evaluate the precise Charpy values, and therefore, additional experiments are to be conducted for more detailed discussion. However, large Charpy values and elastic shape recovery of $\mathrm{CR}+\mathrm{CL}$ suggest their excellent toughness under impact bending.

These results suggest that moderate compression of wood enables the fabrication of soft, elastic, and tenacious composite beams when the wood is appropriately aligned and reinforced.

\section{Strain of composite beam in bending}

In Figure 8, the surface strains of $\mathrm{CR}$ and $\mathrm{CR}+\mathrm{CL}_{0.2}$ are plotted against the bending deflections. Both 
tensile and compressive strains are increased linearly by bending. In the bending of $\mathrm{CR}$, the absolute values of the tensile and compressive strains are nearly equal, suggesting that the tensile and compressive Young's moduli of the $\mathrm{CR}$ are similar. However, the tensile strain of $\mathrm{CR}+\mathrm{CL}_{0.2}$ is restricted by the reinforcement with $\mathrm{CL}$, while large compressive strains are supported by the soft and elastic CR. Similar asymmetric strains are observed in the bending of bamboo culm, in which the tensile surface is reinforced by rigid bundle sheaths, while large compressive strains are allowed by the cellular deformation of the soft parenchyma cells (Obataya et al. 2007).

In the four-point bending test, the position of the neutral plane can be simply calculated from the surface strains, because no shear stress is induced. Figure 9 shows the relative position of the neutral planes as a function of the relative thickness of CL. By reinforcing with CL, the position of the neutral plane shifts to the tensile side, but this trend is reversed with increases in the relative thickness of CL. This trend agrees well with calculated results based on the average Young's moduli of $\mathrm{CR}$ and $\mathrm{CL}$.

We now address the role of $\mathrm{CL}$ in the composite beam. Although the CR shows excellent elasticity under compression, the tensile deformation is less elastic, i.e., more plastic. Therefore, plastic deformation of the tensile side reduces the elastic deflection of CR. When the tensile side of the CR is reinforced with CL, the CR is always in compression, while the large tensile stress is supported by CL. Consequently, both the rigidity and elastic deflection of CR are enhanced by reinforcement with thin $\mathrm{CL}$, as exhibited in Fig. 6 with $\mathrm{CR}+\mathrm{CL}_{0.1}$. However, thicker $\mathrm{CL}$ decreases the ductility and increases the rigidity of the composite beam. Thus, to maximize the ductility and elasticity of the $\mathrm{CR}+\mathrm{CL}$ composite beam, the thickness of CL should be minimized, as the neutral plane is placed near the border of CR and CL. In the present case, the relative thickness of CL is optimized as 0.1. In fact, most mechanical performances of the $\mathrm{CR}+\mathrm{CL}$ composite beams were maximized when the relative thickness of CL was 0.1 or 0.2 .

\section{Viscoelastic shape recovery of composite beam}

This study focuses on the elastic behaviors of compressed wood, but the CR+CL is not purely elastic, instead showing viscoelastic qualities. Figure 10 exhibits the time-dependent shape recovery of a $\mathrm{CR}+\mathrm{CL}_{0.1}$ composite beam. The straight beam shown in (a) is bent once (b) and then offloaded (c). Just after the removal of the load, certain deflection remains unrecovered, but the remaining deflection is gradually diminished with elapsed time. Six hours later, the shape of the beam is 
recovered almost completely (d). This indicates that the deformation of CR is viscoelastically recovered by the remaining stress in the elastic CL. Figure 11 shows the shape recovery of $C R+\mathrm{CL}_{0.1}$ at different loading levels (LL). The LL is defined as the load applied to the beam divided by the maximum load. When a large load is applied $(\mathrm{LL}=80 \%)$, the shape of the beam is not recovered, even after $6 \mathrm{~h}$, probably because of irreversible failure in the CL. However, when smaller loading is applied (LL $\leq 60 \%$ and initial deflection $\leq 20 \mathrm{~mm}$ ), the shape of the beam is recovered completely within a few hours, suggesting excellent recoverability. Further investigation is required to clarify the viscoelastic properties of $\mathrm{CR}$ and $\mathrm{CR}$-based composites; the low resilient response of the composites may have fascinating applications in damping materials used in furniture and construction.

\section{Conclusions}

Moderately compressed cedar lumber was made into a beam with the $\mathrm{R}$ direction aligned in the longitudinal direction of the beam. The CR beam showed excellent ductility and elasticity, comparable to those of hard rubbers. The flexural elasticity of the CR was further improved when the tensile side was reinforced with a thin wooden plate $(\mathrm{CL})$. The $\mathrm{CR}+\mathrm{CL}$ composite beam exhibited large deflections 10 times greater than that of the original cedar lumber, a large Charpy value comparable to that of densified wood, and large critical bending work exceeding that of uncompressed wood in the fiber direction. The ductile and tenacious nature of the composite beam was attributed to the softness and elasticity of the moderately compressed wood, in which the folded wood cell wall acted as flat springs. Further investigations will clarify the viscoelastic behaviors of moderately compressed wood.

\section{Acknowledgement}

The authors are very grateful to the LIXIL JS foundation for their financial support.

\section{References}

Haller P, Wehsener J, Werner TE, Hartig J (2013) Recent advancements for the application of moulded wooden tubes as structural elements. In: Material and Joints in Timber Structures. (Ed), Aicher S, Reinhard HW, Garrecht H, Springer, Heidelberg. pp. 99-108

Inoue M, Norimoto, M, Tanahashi M, Rowell RM (1993) Steam or heat fixation of compressed 
wood. Wood Fiber Sci 25: 224-235

Ito Y, Tanahashi M, Shigematsu M, Shinoda Y (1998) Compressive-molding of wood by high-pressure steam-treatment: Part 2. Mechanism of permanent fixation. Holzforschung 52: $217-221$

Kutnar A, Sandberg D, Haller P (2015) Compressed and moulded wood from processing to products - a review. Holzforschung, DOI: 10.1515/hf-2014-0187

Obataya E, Kitin P, Yamauchi H (2007) Bending characteristics of bamboo (Phyllostachys pubescens) with respect to its fiber-foam composite structure. Wood Sci Technol 41:385-400

Sandberg D, Haller P, Navi P (2012) Thermo-hydro and thermo-hydro-mechanical wood processing: An opportunity for future environmentally friendly wood products. Wood Mat Sci Eng 8: 64-88

Nakamura S, Futamura S, Maeno K, Yoshitani K, Tanahashi M (2009) Development of stretchable and flexible wood which possesses optimum properties for three-dimensional molding (in Japanese). Mokuzai Gakkaishi 55: 77-84

Stamm AJ, Seborg RM (1941) Resin-treated, laminated, compressed wood. Trans Am Chem Eng 37: $385-398$

Stamm AJ, Burr HK, Kline AA (1946) Staybwood. Heat-stabilized wood. Ind Eng Chem 38: $630-634$

Wehsener J, Weser T, Haller P, Diestel O, Cherif C (2014) Textile reinforcement of multidimensional formable wood. Eur J Wood Prod 72: 463-475 
Table 1. Dimensions of beams used for different bending tests.

\begin{tabular}{|c|c|c|c|c|c|}
\hline Test & \multicolumn{2}{|c|}{ Type of beam } & & Width & Length \\
\hline \multirow{3}{*}{$\begin{array}{l}\text { Three- and } \\
\text { four-point } \\
\text { bending }\end{array}$} & Solid & $\mathrm{UL}, \mathrm{CL}$ & 10 & \multirow{3}{*}{10} & \multirow{3}{*}{200} \\
\hline & \multirow{2}{*}{ Composite } & UR, CR & $10 \sim 7$ & & \\
\hline & & CL & $0 \sim 3$ & & \\
\hline \multirow{3}{*}{$\begin{array}{l}\text { Impact bending } \\
\text { (Charpy test) }\end{array}$} & Solid & $\mathrm{UL}, \mathrm{CL}, \mathrm{CR}$ & 30 & \multirow{3}{*}{30} & \multirow{3}{*}{300} \\
\hline & \multirow{2}{*}{ Composite } & $\mathrm{UR}, \mathrm{CR}$ & $30 \sim 21$ & & \\
\hline & & CL & $0 \sim 9$ & & \\
\hline
\end{tabular}




\section{Figure captions}

Figure 1 Structure and fiber alignment of uncompressed beam (UR and UL), compressed beam $(\mathrm{CR})$, reinforcement plate (CL), and composite beams (UR+CL and CR+CL).

$\mathrm{L}, \mathrm{R}$, and $\mathrm{T}$ indicate longitudinal, radial, and tangential directions of wood, respectively. The dimensions of beams are listed in Table 1 .

Figure 2 Compressive stress-strain diagrams of cedar wood.

Circles, uncompressed wood; squares, previously compressed by 50\%; open plots, first compression; filled plots, second compression.

Figure 3 Effects of initial compressive strain on the remaining compressive strain of cedar wood.

Open circles, uncompressed wood; open triangles, previously compressed by $23 \%$; filled circles, $49 \%$; filled triangles, $57 \%$; filled squares, $62 \%$; filled diamonds, $65 \%$.

Figure 4 Failure of uncompressed beam (UL) at small deflection and ductile bending of composite beam $\left(\mathrm{CR}+\mathrm{CL}_{0.1}\right)$ under three-point bending test.

Figure 5 Load-deflection curves of tested beams.

UL, uncompressed wood in L direction; CL, compressed wood in L direction; CR, compressed wood in $\mathrm{R}$ direction; $\mathrm{CR}+\mathrm{CLx}$, composite of $\mathrm{CR}$ and $\mathrm{CL}$ where $\mathrm{x}$ indicates the relative thickness of CL.

Figure 6 Flexural rigidity $(E I)$ of tested beams plotted against elastic deflection.

Open circle, uncompressed wood in L direction (straight grain); open triangles, compressed wood in

L direction (flat grain); open squares, composite beam (UR+CL); filled squares, composite beam $(\mathrm{CR}+\mathrm{CL})$.

Values next to plots indicate the relative thickness of CL. Bars indicate standard deviations.

Figure 7 Average Charpy values of tested beams.

$\mathrm{UL}$, uncompressed wood in $\mathrm{L}$ direction (straight grain); CL, compressed wood in $\mathrm{L}$ direction (flat grain); UR, uncompressed wood in R direction; UR+CLx, composite beams consisting of UR and $\mathrm{CL}$; CR, compressed wood in R direction; CR+CLx, composite beams consisting of CR and CL. 
$\mathrm{x}$ indicates relative thickness of $\mathrm{CL}$ in the composite beams. Bars indicate standard deviations.

Figure 8 Surface strains of compressed wood as a function of deflection under four-point bending. Open plots, compressed wood in $\mathrm{R}$ direction $(\mathrm{CR})$; filled plots, composite beam $\left(\mathrm{CR}+\mathrm{CL}_{0.2}\right)$; squares, tensile strain at the lower surface of the beam; circles, compressive strain at the upper surface of the beam.

Figure 9 Relative position of neutral plane of composite beams (CR+CL) under four-point bending plotted against the relative thickness of CL.

Solid curve indicates the results of calculation based on the average Young's moduli of CR and CL.

Figure 10 Viscoelastic shape recovery of composite beam $\left(\mathrm{CR}+\mathrm{CL}_{0.1}\right)$ after the removal of load.

(a), Before loading; (b), loaded; (c), six seconds after the removal of the load; (d), six hours after the removal of the load.

Figure 11 Changes in remaining deflection of composite beam $\left(\mathrm{CR}+\mathrm{CL}_{0.1}\right)$ with elapsed time after the removal of load.

Different symbols indicate different loading levels (LL) and initial deflections (ID). 


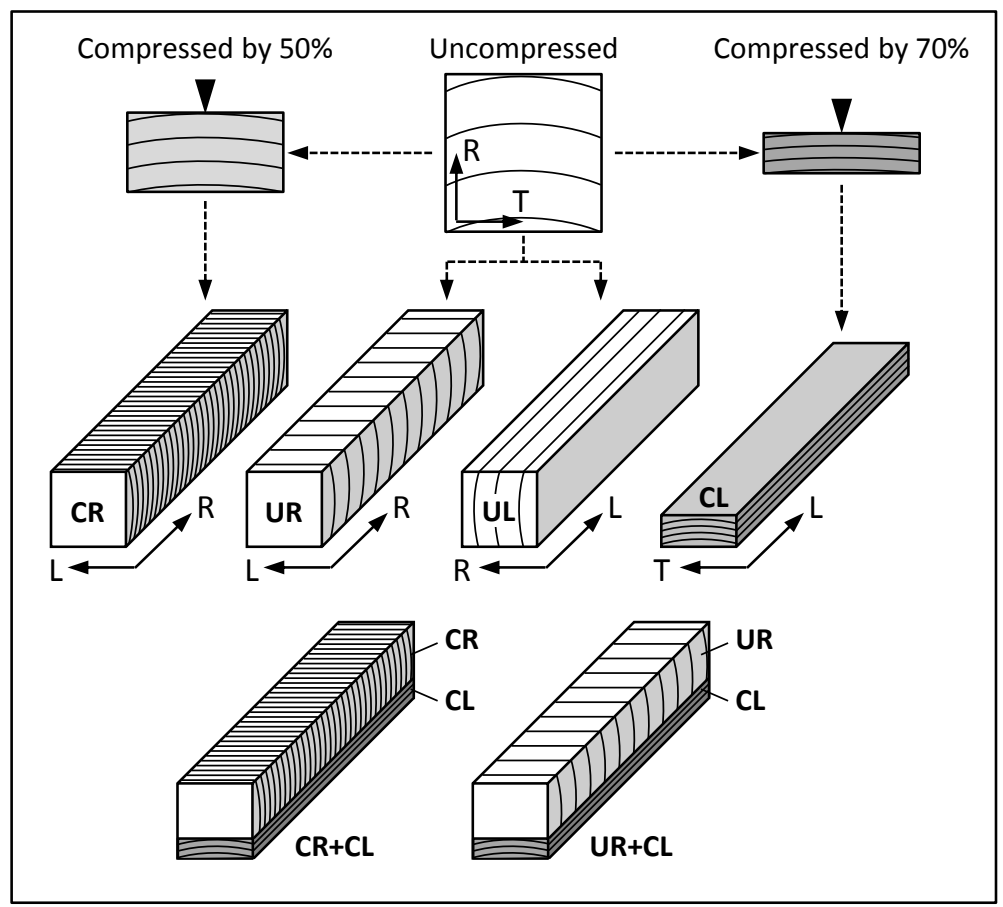

Figure 1 Structure and fiber alignment of uncompressed beam (UR and UL), compressed beam $(C R)$, reinforcement plate $(C L)$ and composite beams (UR+CL and $\mathrm{CR}+\mathrm{CL}$ ).

$L, R$ and $T$ indicate longitudinal, radial and tangential directions of wood, respectively. The dimensions of beams are listed in Table 1. 


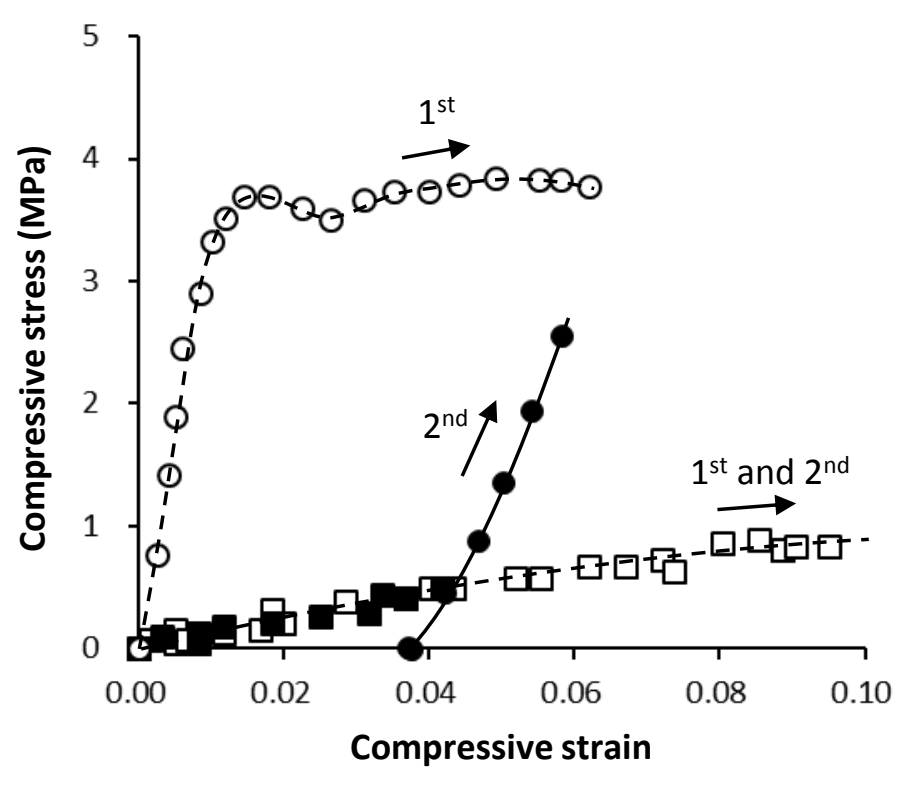

Figure 2 Compressive stress-strain diagrams of cedar wood.

Circles, uncompressed wood; squares, previously compressed by $50 \%$; open plots, first compression; filled plots, second compression. 


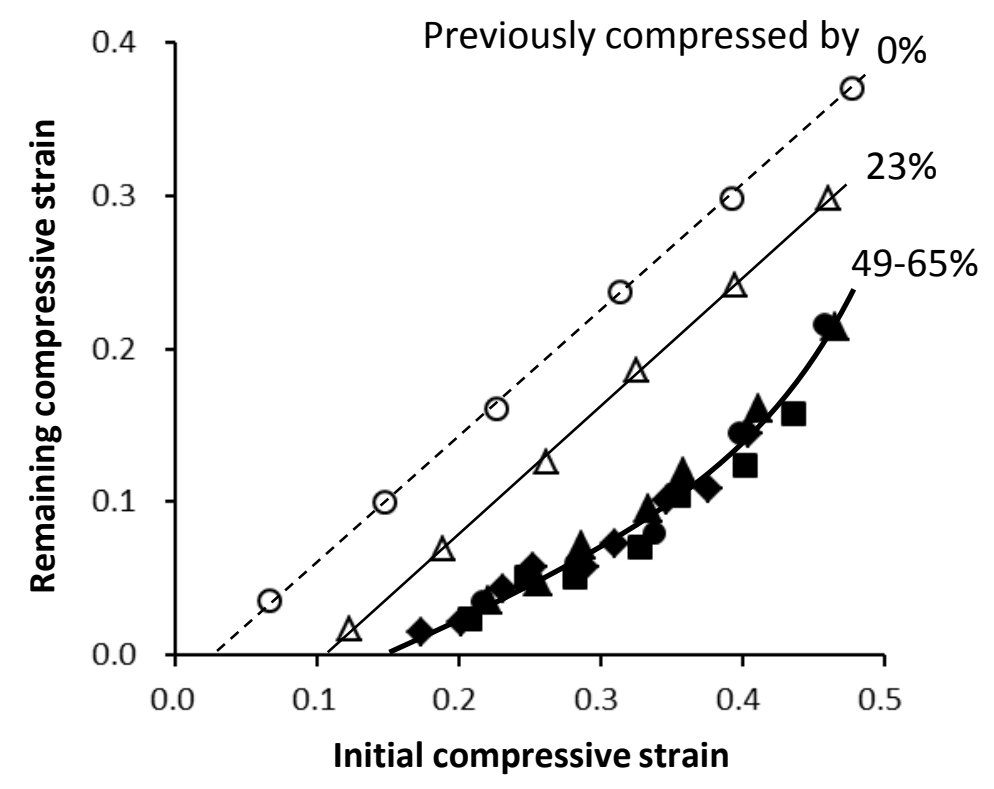

Figure 3 Effects of initial compressive strain on the remaining compressive strain of cedar wood.

Open circles, uncompressed wood; open triangles, previously compressed by $23 \%$; filled circles, $49 \%$; filled triangles, $57 \%$; filled squares, $62 \%$; filled diamonds, $65 \%$. 

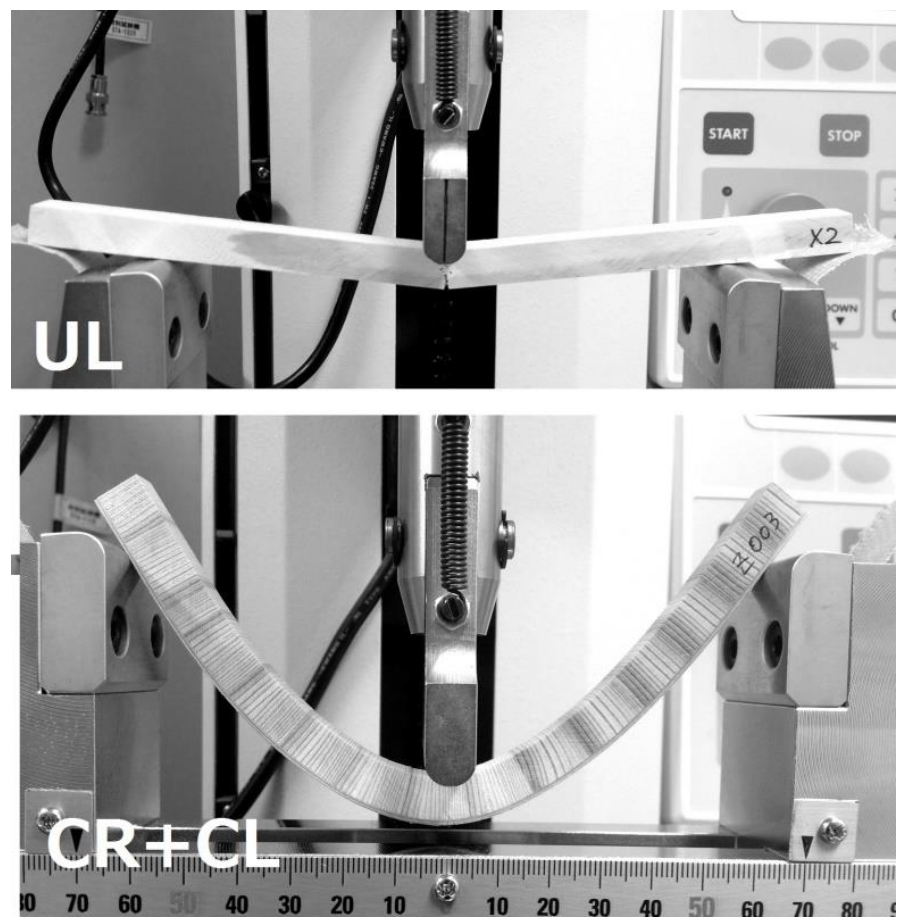

Figure 4 Failure of uncompressed beam (UL) at small deflection and ductile bending of composite beam $\left(C R+\mathrm{CL}_{0.1}\right)$ under three-point bending test. 


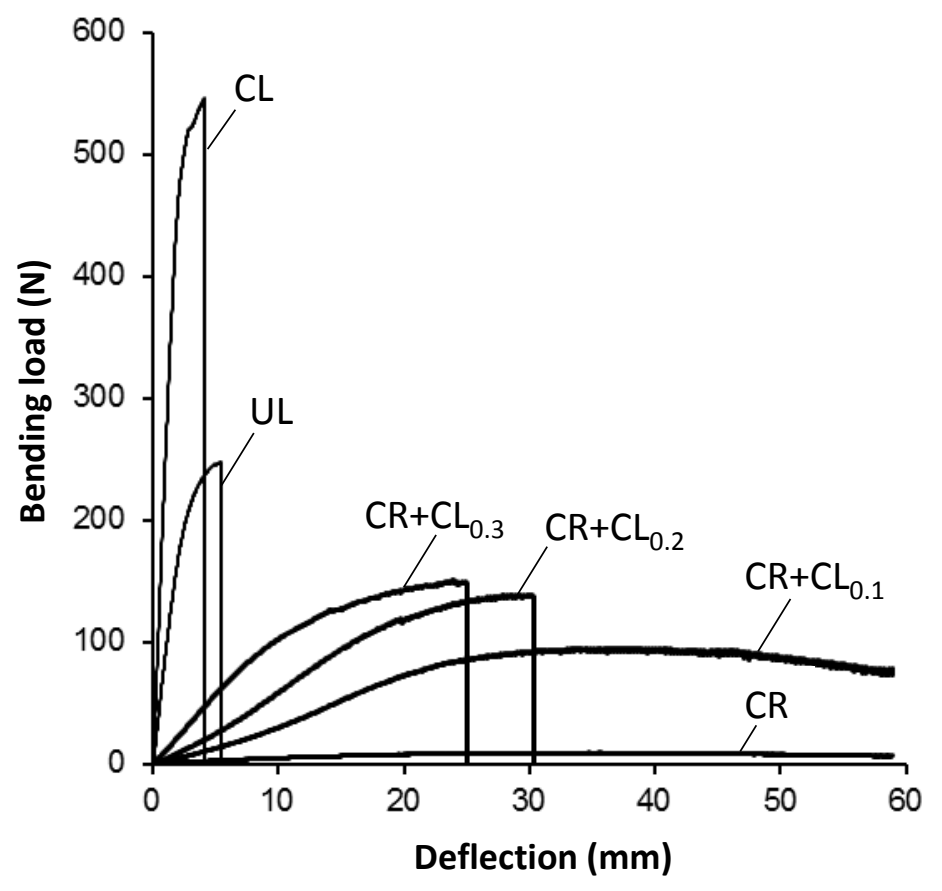

Figure 5 Load-deflection curves of tested beams.

$\mathrm{UL}$, uncompressed wood in $\mathrm{L}$ direction; $\mathrm{CL}$, compressed wood in $\mathrm{L}$ direction; $\mathrm{CR}$, compressed wood in $\mathrm{R}$ direction; $\mathrm{CR}+\mathrm{CLx}$, composite of $\mathrm{CR}$ and $\mathrm{CL}$ where $\mathrm{x}$ indicates the relative thickness of $\mathrm{CL}$. 


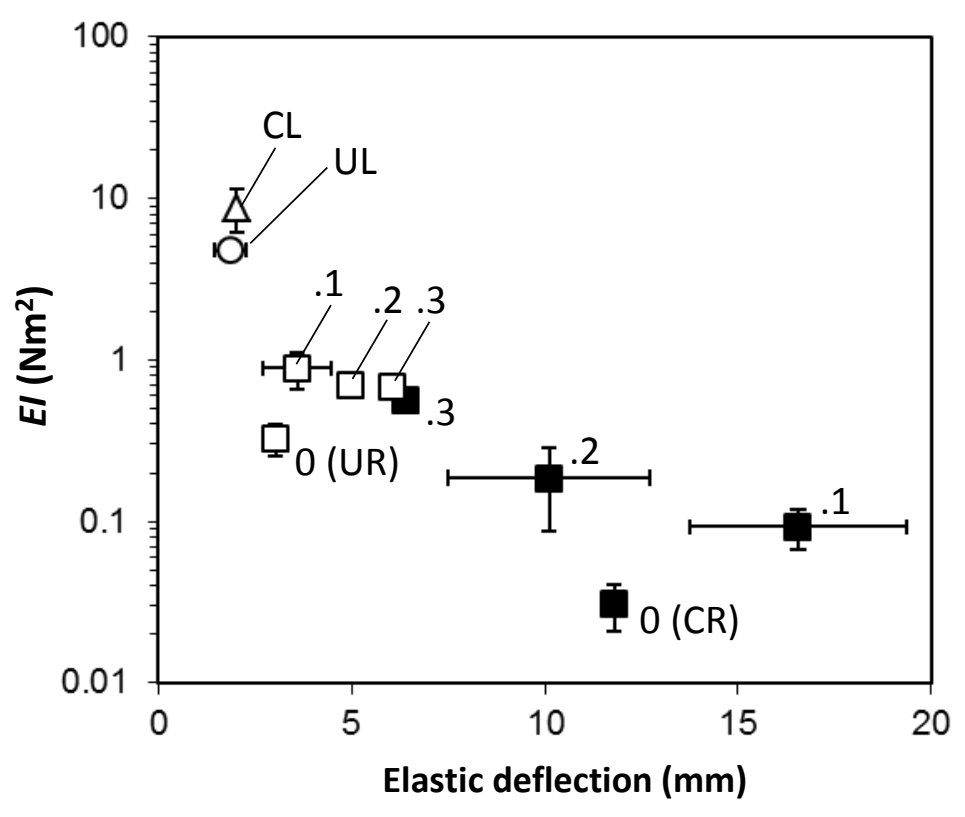

Figure 6 Flexural rigidity (EI) of tested beams plotted against elastic deflection. Open circle, uncompressed wood in L direction (straight grain); open triangles, compressed wood in L direction (flat grain); open squares, composite beam (UR+CL); filled squares, composite beam $(\mathrm{CR}+\mathrm{CL})$.

Values next to plots indicate the relative thickness of $\mathrm{CL}$. Bars indicate standard deviations. 


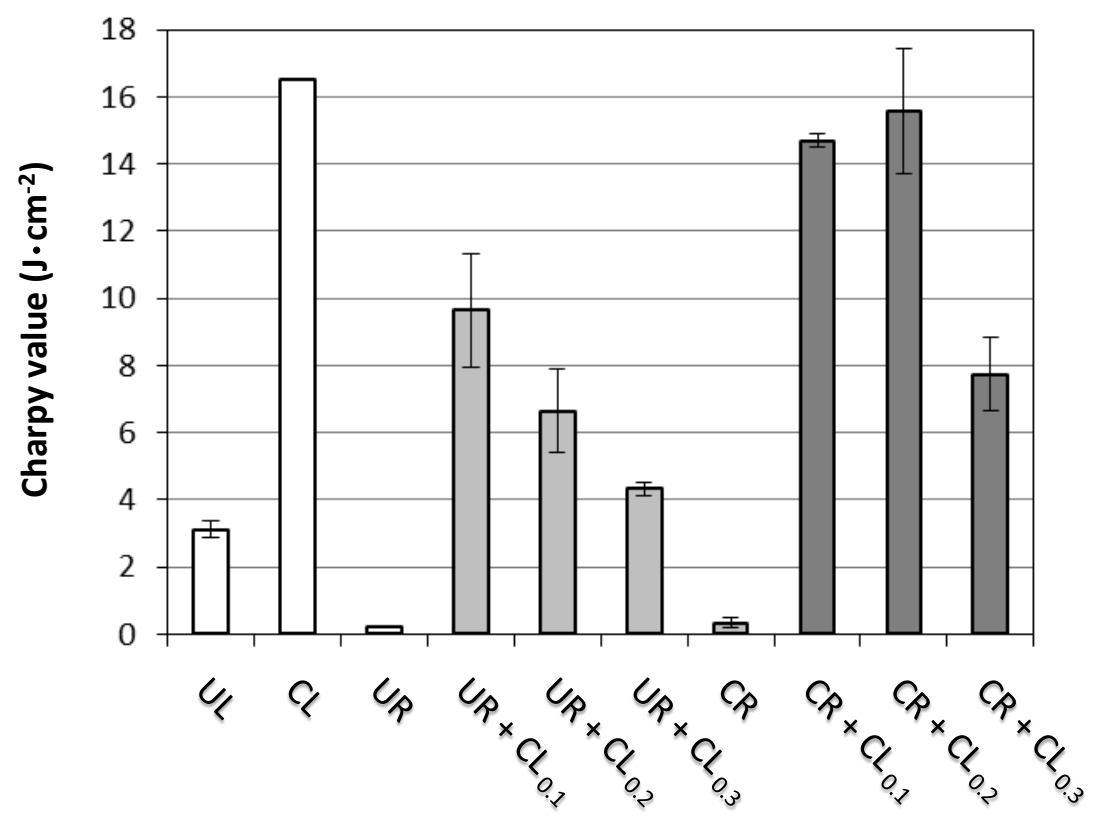

Figure 7 Average Charpy values of tested beams.

UL, uncompressed wood in L direction (straight grain); $C L$, compressed wood in $\mathrm{L}$ direction (flat grain); UR, uncompressed wood in R direction; UR+CLx, composite beams consisting of $U R$ and $C L$; $C R$, compressed wood in $R$ direction; $C R+C L x$, composite beams consisting of $\mathrm{CR}$ and $\mathrm{CL}$.

$\mathrm{x}$ indicates relative thickness of $\mathrm{CL}$ in the composite beams. Bars indicate standard deviations. 


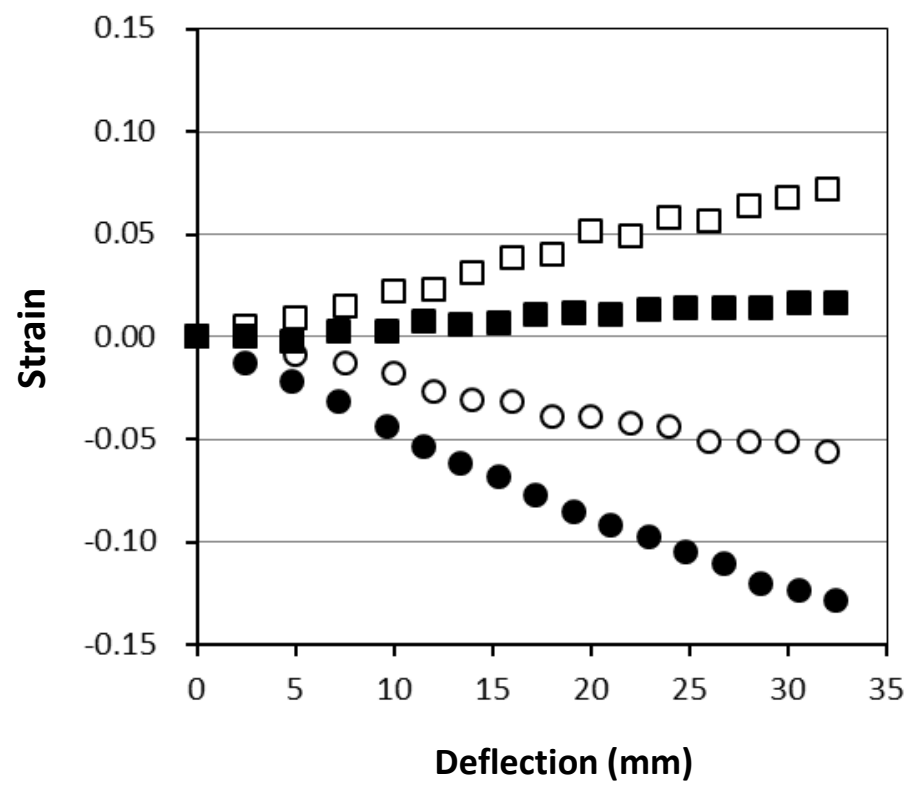

Figure 8 Surface strains of compressed wood as a function of deflection under four-point bending.

Open plots, compressed wood in $\mathrm{R}$ direction (CR); filled plots, composite beam $\left(\mathrm{CR}+\mathrm{CL}_{0.2}\right)$; squares, tensile strain at the lower surface of the beam; circles, compressive strain at the upper surface of the beam. 


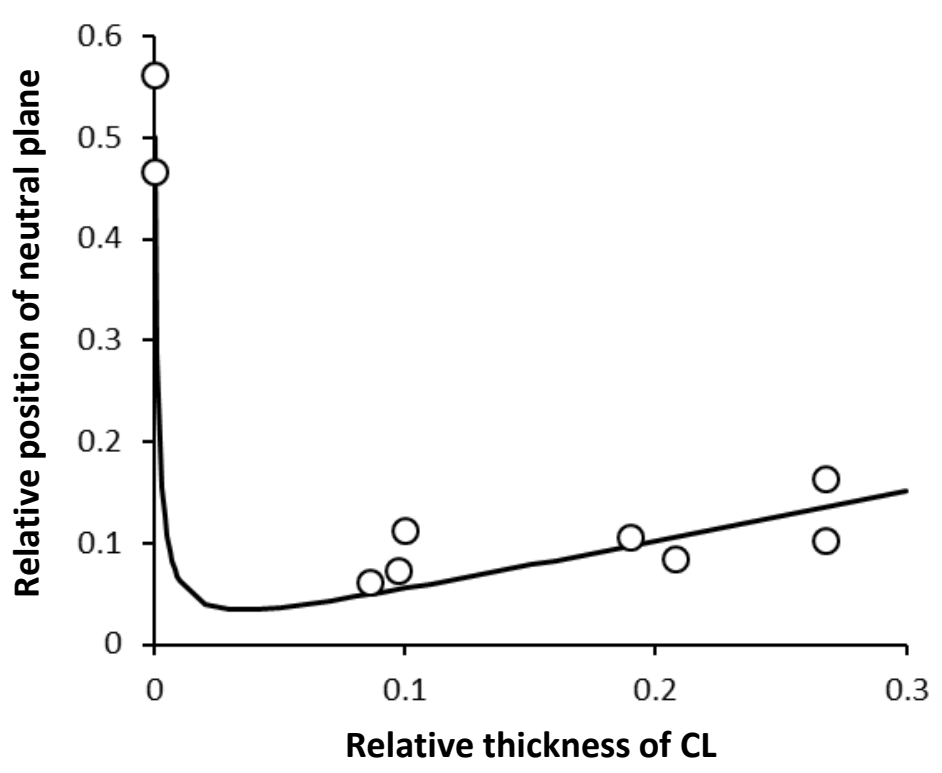

Figure 9 Relative position of neutral plane of composite beams $(C R+C L)$ under four-point bending plotted against the relative thickness of $\mathrm{CL}$. Solid curve indicates the results of calculation based on the average Young's moduli of $\mathrm{CR}$ and $\mathrm{CL}$. 


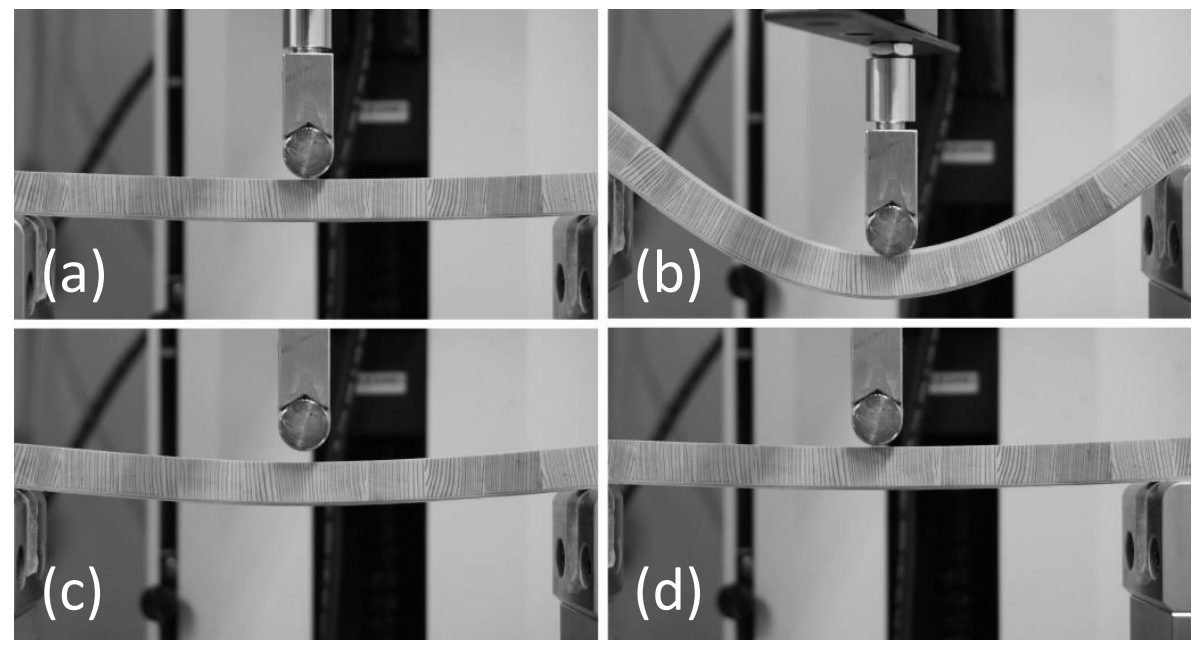

Figure 10 Viscoelastic shape recovery of composite beam $\left(C R+\mathrm{CL}_{0.1}\right)$ after the removal of load.

(a), Before loading; (b), loaded; (c), six seconds after the removal of the load; (d), six hours after the removal of the load. 


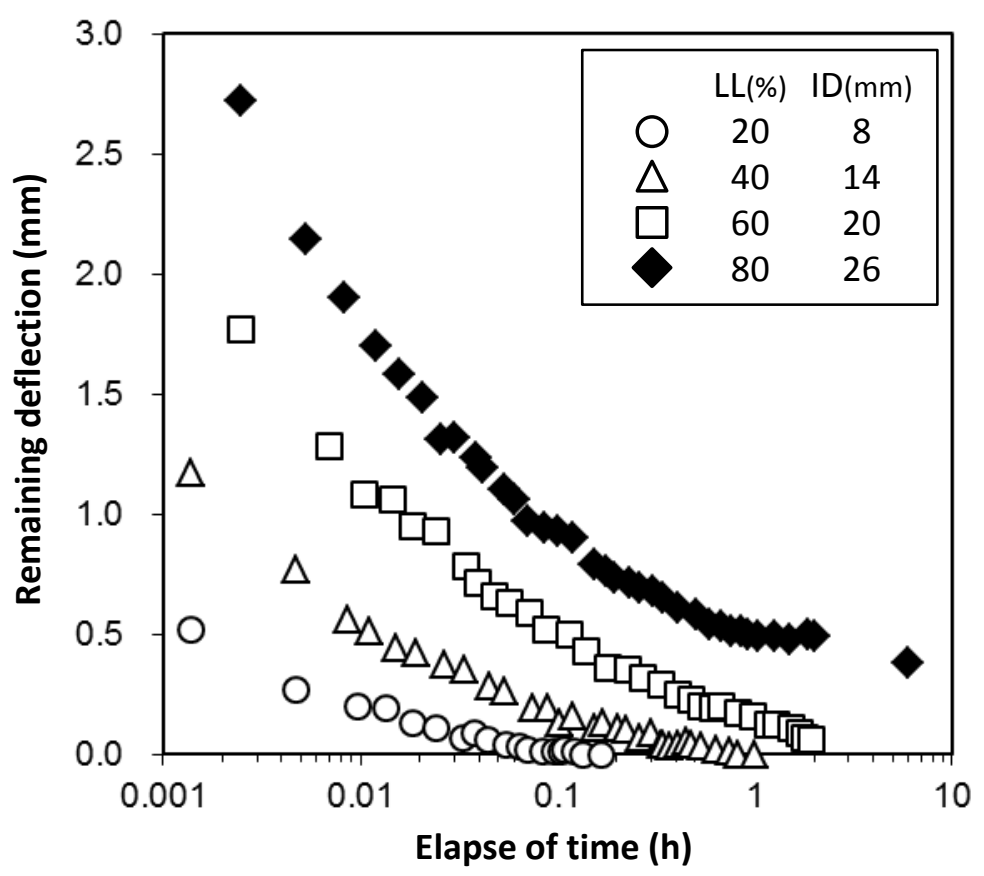

Figure 11 Changes in remaining deflection of composite beam $\left(C R+C L_{0.1}\right)$ with elapsed time after the removal of load.

Different symbols indicate different loading levels (LL) and initial deflections (ID). 